\title{
Avulsion of puborectalis muscle and other risk factors for cystocele recurrence: a 2-year follow-up study
}

\author{
Mirjam Weemhoff • Tineke F. M. Vergeldt • \\ Kim Notten • Jan Serroyen • \\ Paul H. N. M. Kampschoer • Frans J. M. E. Roumen
}

Received: 3 January 2011 / Accepted: 21 July 2011 /Published online: 6 August 2011

(C) The Author(s) 2011. This article is published with open access at Springerlink.com

\begin{abstract}
Introduction and hypothesis This study aimed to determine the relationship of recurrent cystocele with avulsion of puborectalis muscle and other risk factors.

Methods In this prospective observational cohort study, 245 women undergoing anterior colporrhaphy were invited for a 2-year follow-up visit consisting of a questionnaire, physical examination, and translabial 3D ultrasonography. Women with and without recurrent cystocele were compared to identify recurrence risk factors.

Results Of the 245 women, 156 agreed to the follow-up visit (63.7\%). Objective recurrence rate was 80 of $156(51.3 \%)$. Seventeen of the $156(10.9 \%)$ reported subjective recurrence. Risk factors for anatomical recurrence were complete avulsion of puborectalis muscle (OR, 2.4; 95\% CI, 1.3, 4.7), advanced preoperative stage $(\mathrm{OR}, 2.0 ; 95 \% \mathrm{CI}, 1.0,4.1)$, family history of prolapse (OR, 2.4; 95\% CI, 1.2, 4.9), and sacrospinous fixation (OR, 6.5; 95\% CI, 2.0, 21.2).

Conclusions Risk factors for anatomical cystocele recurrence after anterior colporrhaphy were complete avulsion of puborectalis muscle, advanced preoperative stage, family history of prolapse, and sacrospinous fixation.
\end{abstract}

\footnotetext{
M. Weemhoff $(\varangle) \cdot$ T. F. M. Vergeldt $\cdot$ K. Notten

Department of Obstetrics \& Gynecology, GROW, School for Oncology and Developmental Biology, Maastricht University Medical Centre,

PO Box 5800, 6202 AZ Maastricht, The Netherlands

e-mail: m.weemhoff@mumc.nl
}

\section{J. Serroyen}

Department of Methodology and Statistics, Maastricht University, Maastricht, The Netherlands

P. H. N. M. Kampschoer · F. J. M. E. Roumen Department of Obstetrics \& Gynecology, Atrium Medical Centre, Limburg, The Netherlands
Keywords Anterior colporrhaphy - Cystocele - Avulsion of puborectalis muscle $\cdot$ Recurrence $\cdot$ Risk factors $\cdot$ Translabial 3D ultrasonography

\section{Introduction}

The estimated lifetime risk of a woman for undergoing surgery for pelvic organ prolapse or urinary incontinence is $11.1 \%$. These operations are known to have a high reoperation rate $(30 \%)$ because of primary failure and secondary recurrence [1]. The anterior compartment is most commonly affected in pelvic organ prolapse and is also the most prone for recurrence after surgery $[2,3]$.

Little is known about the factors associated with failure of surgical correction. Probably, the factors that play a role in the occurrence of pelvic organ prolapse in the first place are also risk factors for recurrence of prolapse after surgery. Risk factors for pelvic organ prolapse that have been described in literature are aging [4, 5], obesity [4, 6], family history of prolapse [7, 8], and collagen weakness [5]. Furthermore, there is a strong relationship between vaginal child birth and pelvic organ prolapse [4, 7, 9]. Vaginal birth gives a 4- to 11-fold increase in risk for developing pelvic organ prolapse among parous women compared to women without vaginal delivery in their history [10]. It has been postulated that avulsions of the puborectalis muscle are the intermediary between vaginal deliveries and pelvic organ prolapse [11].

Studies with MR imaging and pelvic floor ultrasound have demonstrated the occurrence of trauma to the levator ani after vaginal birth. In $20-23 \%$ of women who had delivered vaginally, trauma of the levator ani was identified $[12,13]$. No defects were seen in nulliparous women. Pelvic organ prolapse was seen in $83 \%$ of women with 
levator defects and in $44 \%$ women without levator defects. The association was strongest for cystocele and uterine prolapse. Furthermore, women with prolapse appeared to have more major levator defects than controls without prolapse (55\% compared with $16 \%)$. Women with and without prolapse were equally likely to have minor defects [14].

The aim of the present study was to estimate the rates of anatomical and subjective recurrence after anterior colporrhaphy to determine whether avulsion of the puborectalis muscle is a risk factor for recurrence of cystocele and to identify other risk factors associated with recurrence.

Identifying patients at risk for recurrent pelvic organ prolapse after surgery offers the opportunity for individualizing counseling and adapting treatment and prevention to the individual risk of recurrence.

\section{Methods}

Between January 2006 and September 2008, 245 women undergoing an anterior colporrhaphy were enrolled in a multicentre randomized controlled trial comparing indwelling catheterization for 2 and 5 days following surgery respectively [15]. Two years later, these women were approached again and invited to participate in a follow-up study. The aim of this study was to estimate the rates of anatomical and subjective recurrence of cystocele 2 years after anterior colporrhaphy to determine whether avulsion of the puborectalis muscle is a risk factor for recurrence of cystocele and to identify other risk factors associated with this recurrence.

Patients were localised by the address and telephone number that was registered in the hospitals. All patients received written information and were contacted by telephone to ask them for participation to this follow-up study. Patients that agreed to participate were invited for a follow-up visit at the outpatient clinic consisting of a validated questionnaire, a physical examination, and translabial 3D ultrasonography of the pelvic floor. Patients who did not agree with a follow-up visit were invited to complete the questionnaire at home.

The questionnaire that was used was a validated Dutch version of the Urinary Distress Inventory (UDI) $[16,17]$ and the Defecation Distress Inventory [18]. Questions concerning possible risk factors were added, including weight, length, parity, assisted deliveries, and family history of prolapse (defined as mother or sister with prolapse).

Pelvic examination was performed with the patient in the lithotomy position. Clinical staging of pelvic organ prolapse according to the Pelvic Organ Prolapse Quantification (POPQ) classification system was performed [19]. The examiner was blinded for the patients' answers to the questionnaire and for the results of the ultrasound examination.
A translabial ultrasonography of the pelvic floor was performed in supine position with hips flexed and slightly abducted and after voiding. A GE Voluson 730 expert system (GE Kretz Ultrasound, Zipf, Austria) was used with a 4.8 MHz curved abdominal transducer covered with gel and a condom. The transducer was placed against the perineum in the mid-sagittal plane with a maximum angle of $70^{\circ}$ for $2 \mathrm{D}$ imaging. If the (1) symphysis pubis, (2) urethra, (3) anal canal, and (4) levator ani were visualized in one plane, an axial 4D volume was rendered with a maximum angle of $85^{\circ}$ to visualize the hiatus of minimal dimensions. In this plane, a 4D volume cine was recorded containing a maximal pelvic muscle contraction to detect abnormal insertion of the puborectalis muscle on the inferior pubic ramus (Fig. 1). This method has been described by Dietz and has been shown to be reproducible [20, 21].

The recorded data sets were analysed offline using Voluson GE Kretz 4D-view V 5.1 software (GE Kretz Ultrasound, Zipf, Austria). The ultrasonographers were blinded for the outcome of the questionnaire and pelvic examination. With tomographic ultrasound imaging, a technique to show the levator ani muscle in multiple slices of $2.5 \mathrm{~mm}$, levator damage was graded according to the scoring system described by Dietz et al. [22]. A complete avulsion was diagnosed on tomographic ultrasound if all three central slices, i.e., the plane of minimal dimensions plus slices 2.5 and $5 \mathrm{~mm}$ cranial to this plane, show an abnormal insertion of the puborectalis muscle on the inferior pubic ramus. Several authors have demonstrated the clinical relevance of a complete avulsion as compared to no or only a partial avulsion of the puborectalis muscle for the development of pelvic organ prolapse [14, 22].

Data collected during the follow-up visits and from the returned questionnaires were entered into an existing database. Data on the patients' history, the performed operation, and the surgical technique used had been collected prospectively during the original randomized controlled trial (RCT) in 2008 on indwelling catheterization. During that RCT, the preoperative grade of prolapse was staged according to the Baden-Walker classification as the POPQ classification was not generally introduced in daily practice yet. Stage I was a cystocele into the first half of the vagina; in stage II, the prolapse protruded into the distal half of the vagina; in stage III, the prolapsed tissue bulged out of the vagina; and in stage IV, there was a total protrusion of the anterior wall of the vagina.

Anatomical recurrence was defined as an anterior vaginal wall prolapse equal to or greater than stage II of the POPQ classification. Subjective recurrence was defined as (1) feeling and/or (2) seeing a vaginal bulge, with at least a judgement of one of these two symptoms as moderately bothersome, or both of these two symptoms as somewhat bothersome, according to the scoring system of the validated UDI questionnaire. 
Fig. $13 \mathrm{D}$ ultrasonography of levator muscle. 3D ultrasonography. Right side the mid-sagittal plane, left side the rendered 3D volume of the levator ani muscle. Normal insertion of the puborectalis muscle, no avulsion. 1 Bladder, 2 urethra, 3 central axis of symphysis, 4 anal canal, 5 levator muscle, 6 urethra, 7 vagina, 8 anal canal, 9 levator sling

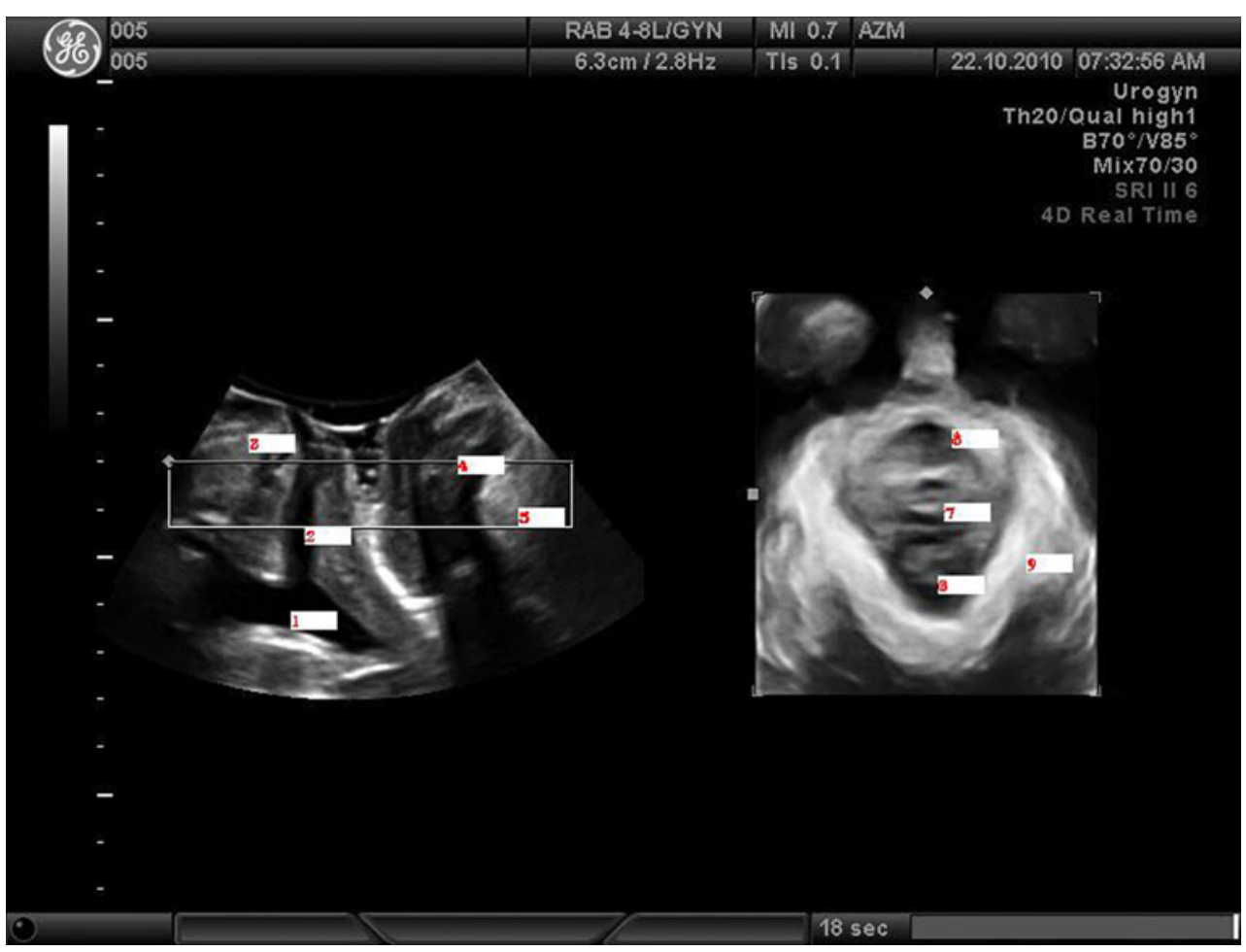

The statistical analysis was performed using the statistical software package SPSS version 16.0 for windows. Women with and without recurrent cystocele were compared to assess the association with age, body mass index (BMI), parity, cystocele stage III or IV before surgery (BadenWalker classification), assisted deliveries, family history of prolapse (defined as mother or sister with prolapse), constipation, number of compartments involved, combination with vaginal sacrospinous fixation, previous prolapse surgery, and complete avulsions of puborectalis muscle.

The independent sample $t$ test was used to compare means of continuous responses. The chi-square test was used to compare categorical variables. Fisher's exact test was performed when the assumptions of the Pearson chisquare test were not reached, i.e., one or more cells contained less than five observations. Logistic regression models were employed to calculate odds ratios (OR) and 95\% confidence intervals (CI). A $p<0.05$ was considered statistically significant.

The protocol was approved by the medical ethics committees of each individual participating hospital. All patients who agreed to participate gave written informed consent before enrolment.

\section{Results}

Between November 2009 and April 2010, all 245 participants of a randomized controlled trial focusing on regimen of catheterization after anterior colporrhaphy were asked to participate in a follow-up study 2 years after the initial operation. From the total of 245 women, 156 agreed to a follow-up visit (63.7\%), 222 women returned the questionnaire $(90.6 \%), 23$ women declined to participate $(9.4 \%)$, among whom three women we were unable to localize $(1.2 \%)$, two suffered from dementia $(0.8 \%)$, and one had died at the time of the follow-up study (0.4\%).

Patient characteristics are shown in Table 1. There were no significant differences between women who attended the follow-up visit and women that did not participate with regard to BMI, parity, cystocele stage III or IV before surgery, assisted deliveries, family history of prolapse, constipation, previous prolapse surgery, and concomitant surgery in combination with the anterior colporrhaphy. However, the mean age of women who did not attend the follow-up visit was significantly higher than of those who did not attend.

Table 2 shows the outcome measures of the results of the operation. The mean follow-up interval was 31 months (range, 14-50). Eighty of the 156 patients (51.3\%) had an anatomical recurrence of the cystocele. Of these, 55 women (68.8\%) had a stage II cystocele, 22 women (27.5\%) had a stage III cystocele, and three women (3.8\%) had stage IV cystocele. Seventeen of the 156 women $(10.9 \%)$ reported a subjective recurrence. Of the 80 women with anatomical recurrence, eight $(10.0 \%)$ were symptomatic compared to nine of 76 women $(11.8 \%)$ without anatomical recurrence. Of the nine women with subjective recurrence but no 
Table 1 Patient characteristics

Participants that attended the follow-up visit, $N=156$
Participants of questionnaire only $(n=66)$ and $\quad p$ value refusers to join the study ( $n=23), N=89$

\begin{tabular}{|c|c|c|c|}
\hline Mean age [years $( \pm \mathrm{SD})]$ & $61.4(10.1)$ & $65.8(11.0)$ & $<0.01$ \\
\hline Mean BMI $\left[\mathrm{kg} / \mathrm{m}^{2}( \pm \mathrm{SD})\right]$ & $26.3(3.7)$ & $26.7(4.1)$ & 0.35 \\
\hline Mean parity $[n( \pm \mathrm{SD})]$ & $2.3(1.1)$ & $2.5(1.0)$ & 0.21 \\
\hline Cystocele grade III or IV before surgery $[n(\%)]$ & $76 / 154(49.4 \%)$ & $54 / 88(61.4 \%)$ & 0.07 \\
\hline History of assisted deliveries $[n(\%)]$ & $21 / 156(13.5 \%)$ & $10 / 89(11.2 \%)$ & 0.66 \\
\hline Family history of prolapse $^{\mathrm{a}}[n(\%)]$ & $63 / 156(40.4 \%)$ & $23 / 65(35.4 \%)$ & 0.49 \\
\hline History of constipation ${ }^{\mathrm{a}}[n(\%)]$ & $27 / 154(17.5 \%)$ & $7 / 52(13.5 \%)$ & 0.50 \\
\hline History of previous prolapse surgery $[n(\%)]$ & $17 / 155(11.0 \%)$ & $9 / 89(10.1 \%)$ & 0.84 \\
\hline \multicolumn{4}{|l|}{ Concomitant surgery $[n(\%)]$} \\
\hline Combination with hysterectomy & $85 / 156(54.5 \%)$ & $50 / 89(56.2 \%)$ & 0.80 \\
\hline Combination with posterior repair & $75 / 156(48.1 \%)$ & $45 / 89(50.6 \%)$ & 0.71 \\
\hline Combination with sacrospinal fixation & $22 / 156(14.1 \%)$ & $16 / 89(18.0 \%)$ & 0.42 \\
\hline
\end{tabular}

$S D$ Standard deviation

${ }^{\text {a }}$ Family history of prolapse and constipation were only known in patients who completed the questionnaire

anatomical recurrence, only three cases could be explained by a rectocele. The other six women had no objective anatomical prolapse of any compartment. There was no statistically significant correlation between anatomical and subjective recurrence $(p=0.71)$.

Of the 66 patients that only filled out the questionnaire, 52 women answered the questions concerning subjective recurrence. Of these 52 women, six women (11.5\%) reported subjective recurrence. In total, of all 208 women who filled out the questions concerning subjective recurrence, the subjective recurrence rate was $11.1 \%$.

Table 3 shows the data on avulsions of the puborectalis muscle. In 152 patients, it was possible to analyse the images of the ultrasound examination. In four of the 156 (2.6\%) patients, the ultrasonographists had not been able to visualize all four reference points, and therefore, reading the ultrasound scan was not possible. Thirty of the 152 women $(20 \%)$ had no avulsion, 59 women $(39 \%)$ had a partial avulsion, and 63 women (41\%) had a complete avulsion of the puborectalis muscle. Of the 77 women with an anatomical recurrence, 40 women (52\%) had a complete avulsion of the puborectalis muscle as compared to 23 of 75 women (31\%) without anatomical recurrence. Of the 17 women with a subjective recurrence, only eight women had an anatomical recurrent prolapse in the operated compartment. From these eight women, there was not one person without an avulsion; four women had a partial avulsion, and four women had a complete avulsion of the puborectalis muscle. In this small group of eight women, symptomatic recurrent prolapse was not associated with complete avulsion. Table 4 shows the univariable and multivariable logistic regression analysis of the possible risk factors for anatomical recurrence. Risk factors in univariable analysis for anatomical recurrence were cystocele stage III or IV before surgery, family history of prolapse, sacrospinous fixation, and complete avulsion of puborectalis muscle. These factors appeared to be independent as testing for interaction showed no significance. In multivariable logistic regression analysis, all four variables turned out to be independently associated with anatomical recurrence: cystocele stage III or IV before surgery (OR, $2.0 ; 95 \%$ CI $1.0,4.1$ ), family history of prolapse (OR, 2.4; 95\% CI, 1.2, 4.9), sacrospinous fixation (OR, 6.5; $95 \% \mathrm{CI}, 2.0,21.2)$, and complete avulsion of puborectalis muscle (OR, 2.3; 95\% CI, 1.1, 4.8).
Table 2 Recurrence rates of cystocele 2 years after anterior colporraphy

\begin{tabular}{lr}
\hline & Recurrence rates \\
\hline Patients with anatomical recurrence & $80 / 156(53.1 \%)$ \\
Patients with subjective recurrence & \\
Patients that attended the follow-up visit & $17 / 156(10.9 \%)$ \\
Patients that only filled out the questionnaire & $6 / 52(11.5 \%)$ \\
Total population & $23 / 208(11.1 \%)$ \\
Symptomatic patients with anatomical recurrence of cystocele & $8 / 80(10.0 \%)$ \\
\hline
\end{tabular}


Table 3 Avulsion of puborectalis muscle

\begin{tabular}{lllr}
\hline & $\begin{array}{l}\text { No anatomical } \\
\text { recurrence }\end{array}$ & $\begin{array}{l}\text { Anatomical } \\
\text { recurrence }\end{array}$ & Total \\
\hline No avulsion & $21(28 \%)$ & $9(12 \%)$ & 30 \\
Partial avulsion $^{\mathrm{a}}$ & $31(41 \%)$ & $28(36 \%)$ & 59 \\
Complete avulsion $^{\mathrm{a}}$ & $23(31 \%)$ & $40(52 \%)$ & 63 \\
Total & $75(100 \%)$ & $77(100 \%)$ & 152 \\
\hline
\end{tabular}

${ }^{\text {a } U n i l a t e r a l ~ o r ~ b i l a t e r a l ~ a v u l s i o n ~}$

Sacrospinous fixation was performed in 22 of the 156 patients attending the follow-up visit (14.1\%). Of these women, 18 patients had an anatomical recurrence of the cystocele, and of these 18 women, three women (16.7\%) were symptomatic.

Of the 156 women who attended the follow-up visit, eight had a history of previous anterior colporrhaphy before the inclusion in the randomized controlled trial in 2008. Of these eight women, seven had again an anatomical recurrence in this follow-up study. Surprisingly, three of the four women with graft-augmented anterior repair had an anatomical recurrence.

\section{Discussion}

After a mean follow-up of 31 months following an anterior colporrhaphy, our study showed an anatomical recurrence rate of cystocele of $51.3 \%$. Complete avulsion of pubor- ectalis muscle was identified as risk factor for recurrence, along with cystocele stage III or IV before surgery, family history of prolapse, and sacrospinous fixation.

The anatomical cystocele recurrence rate in our study is consistent with the rate of recurrences described in other studies $[23,24]$. Of the women with anatomical cystocele recurrence, only $10.9 \%$ had subjective recurrence. There was no statistically significant association between anatomical and subjective recurrence. This phenomenon has also been described by others $[3,25]$. On the one hand, we know that a single POP-Q exam may miss some women with prolapse because of the timing of the clinical examination on the day or the amount of activity performed by the woman. On the other hand, a considerable overlap exists between patients with and without symptoms in different stages of pelvic organ prolapse [26]. The prevalence of bulge symptoms rises steadily with increasing extent of prolapse along a continuum. Ghetti et al. described how the frequency of bulge symptoms within stage II, varied from $57 \%$ at -1 to $87 \%$ at +1 . Within stages III and IV, up to $90 \%$ of women reported a bothering bulge. The turning point seems to be in stage II [26]. In our study, $68.8 \%$ of women with anatomical recurrence had a POPQ stage II cystocele. This could possibly explain the low subjective recurrence rate in our study.

In our study, complete levator avulsions were associated with anatomical recurrence of cystocele with an odds ratio of 2.3 (95\% CI, 1.1, 4.8). In agreement with our study, others found levator defects to be a risk factor for recurrence too with an odds ratio of OR of 7.0 (95\% CI,

Table 4 Risk factors for anatomical recurrence

\begin{tabular}{|c|c|c|c|c|c|c|c|}
\hline \multirow[t]{2}{*}{ Possible risk factors } & \multirow[t]{2}{*}{$N$} & \multicolumn{3}{|c|}{ Univariate analysis } & \multicolumn{3}{|c|}{ Multivariate analysis } \\
\hline & & OR & $95 \% \mathrm{CI}$ & $p$ value & OR & $95 \% \mathrm{CI}$ & $p$ value \\
\hline Age (years) & 156 & 1.0 & $1.0-1.0$ & 0.83 & & & \\
\hline BMI $\left(\mathrm{kg} / \mathrm{m}^{2}\right)$ & 156 & 1.0 & $0.9-1.1$ & 0.56 & & & \\
\hline Parity & 156 & 0.9 & $0.7-1.2$ & 0.61 & & & \\
\hline Cystocele grade III or IV before surgery & $76 / 154$ & 2.2 & 1. $1-4.1$ & 0.02 & 2.0 & $1.0-4.1$ & 0.05 \\
\hline History of assisted deliveries & $21 / 156$ & 0.8 & $0.3-2.1$ & 0.72 & & & \\
\hline Family history of prolapsed & $63 / 156$ & 2.1 & $1.1-4.0$ & 0.03 & 2.4 & $1.2-4.9$ & 0.02 \\
\hline History of constipation & $27 / 154$ & 1.0 & $0.4-2.3$ & 0.99 & & & \\
\hline History of previous prolapse surgery & $17 / 155$ & 1.4 & $0.5-4.0$ & 0.49 & & & \\
\hline Number of compartments & 156 & & & & & & \\
\hline \multicolumn{8}{|l|}{1 (reference) } \\
\hline 2 & & 1.1 & $0.5-2.5$ & 0.84 & & & \\
\hline 3 & & 0.7 & $0.3-1.8$ & 0.50 & & & \\
\hline Sacrospinous fixation & $22 / 156$ & 5.2 & $1.7-16.3$ & $<0.01$ & 6.5 & $2.0-21.2$ & $<0.01$ \\
\hline Complete avulsion of puborectalis muscle & $63 / 152$ & 2.4 & $1.3-4.7$ & 0.08 & 2.3 & $1.1-4.8$ & 0.02 \\
\hline
\end{tabular}


2.6, 19.1) [24]. As other authors described before, we did not find an association between partial avulsions of puborectalis muscle and anatomical recurrence [14, 22].

In our study, only eight of the 17 women with a subjective recurrence had an anatomical recurrent prolapse in the operated compartment. In these eight women, a symptomatic recurrent prolapse in the operated compartment was surprisingly not associated with a major levator defect. The amount of women with a subjective recurrence of prolapse was too small to generalize this finding, therefore larger studies are needed.

Advanced prolapse grade before surgery was also identified as a risk factor for recurrent pelvic organ prolapse after surgery in other studies [25, 27-29]. The association we identified between recurrence and family history of prolapse has not been found by others [25, 27]. In contrast to our study, several others found an association between recurrence and younger age $[3,25,29]$.

There is only one study in the literature comparing cystocele recurrence rates after anterior colporrhaphy with and without sacrospinous fixation [30]. In that study, cystocele recurrence rate was $11.7 \%$ versus $9.4 \%$ in patients undergoing anterior colporrhaphy with or without concomitant sacrospinous fixation, respectively. It was concluded that cystocele formation was not altered by performing a sacrospinous fixation. In our present study, sacrospinous fixation is a risk factor for anatomical recurrence. We hypothesize that sacrospinous fixation creates an exaggerated posterior vaginal axis resulting in abnormal intraabdominal pressure on the anterior vaginal wall, resulting in an increased risk for recurrent cystocele formation. However, a sacrospinous fixation was performed in only $14.1 \%$ of participants in the follow-up study. Due to the small number of procedures, the OR has a wide $95 \%$ confidence interval $(2.1,22.2)$, which makes this finding less accurate. Further research is indicated.

A weakness of our study is that its accuracy might be challenged because not all women who underwent surgery attended the follow-up visit. On the one hand, it is possible that women with symptoms are more eager to join the study than women without symptoms. On the other hand, it is possible that women who had already been treated for a recurrence are less willing to visit a doctor afterwards. Considering the fact that there are no significant differences in patient characteristics except age and that the percentages of patients with a subjective recurrence are comparable between the group of women that attended the follow-up visit $(10.9 \%)$ and the group of women that only filled out the questionnaire $(11.5 \%)$, this potential bias may be limited.

The mean age of women who did not attend the followup visit was higher compared to the women who attended the follow-up visit. In our study, age was not a significant risk factor for recurrence of cystocele. Therefore, we do not expect this difference in age to influence our results importantly. If younger age is a risk factor for pelvic organ prolapse recurrence, as stated by others [3, 25, 29], our recurrence rate might be an overestimate.

Another limitation of our study was the heterogeneous mix of procedures. However, the performed concomitant procedures are common in normal clinical practice. Therefore, we can state that this study set-up meets daily practice. Our population was predominantly white, limiting the generalizability of our findings to white women.

In conclusion, anatomical recurrence of cystocele after anterior colporrhaphy is high, while subjective recurrences occur less frequently. No significant correlation was found between anatomical recurrence and subjective feeling of recurrence. Risk factors for anatomical recurrence are complete avulsion of puborectalis muscle, advanced stage cystocele preoperatively, family history of prolapse, and sacrospinous fixation.

Acknowledgements We would like to thank Prof. Dr. J.L.H. Evers for reading and commenting the manuscript.

Financial support None.

\section{Conflicts of interest None.}

Open Access This article is distributed under the terms of the Creative Commons Attribution Noncommercial License which permits any noncommercial use, distribution, and reproduction in any medium, provided the original author(s) and source are credited.

\section{References}

1. Olsen AL, Smith VJ, Bergstrom JO, Colling JC, Clark AL (1997) Epidemiology of surgically managed pelvic organ prolapse and urinary incontinence. Obstet Gynecol 89:501-506

2. Hendrix SL, Clark A, Nygaard I, Aragaki A, Barnabei V, McTiernan A (2002) Pelvic organ prolapse in the Women's Health Initiative: gravity and gravidity. Am J Obstet Gynecol 186:1160-1166

3. Miedel A, Tegerstedt G, Morlin B, Hammarstrom M (2008) A 5-year prospective follow-up study of vaginal surgery for pelvic organ prolapse. Int Urogynecol J Pelvic Floor Dysfunct 9:1593-1601

4. Progetto Menopausa Italia Study Group (2000) Risk factors for genital prolapse in non-hysterectomized women around menopause. Results from a large cross-sectional study in menopausal clinics in Italy. Eur J Obstet Gynecol Reprod Biol 93:135-140

5. Amselem C, Puigdollers A, Azpiroz F, Sala C, Videla S, Fernandez-Fraga X et al (2009) Constipation: a potential cause of pelvic floor damage? Neurogastroenterol Motil 22:150-153

6. Moalli PA, Jones Ivy S, Meyn LA, Zyczynski HM (2003) Risk factors associated with pelvic floor disorders in women undergoing surgical repair. Obstet Gynecol 101:869-874

7. Chiaffarino F, Chatenoud L, Dindelli M, Meschia M, Buonaguidi A, Amicarelli F et al (1999) Reproductive factors, family history, occupation and risk of urogenital prolapse. Eur J Obstet Gynecol Reprod Biol 82:63-67 
8. McLennan MT, Harris JK, Kariuki B, Meyer S (2008) Family history as a risk factor for pelvic organ prolapse. Int Urogynecol J Pelvic Floor Dysfunct 19:1063-1069

9. Kim CM, Jeon MJ, Chung DJ, Kim SK, Kim JW, Bai SW (2007) Risk factors for pelvic organ prolapse. Int J Gynaecol Obstet 98:248-251

10. Mant J, Painter R, Vessey M (1997) Epidemiology of genital prolapse: observations from the Oxford Family Planning Association Study. Br J Obstet Gynaecol 104:579-585

11. Dietz HP (2008) The aetiology of prolapse. Int Urogynecol J Pelvic Floor Dysfunct 19:1323-1329

12. DeLancey JO, Kearney R, Chou Q, Speights S, Binno S (2003) The appearance of levator ani muscle abnormalities in magnetic resonance images after vaginal delivery. Obstet Gynecol 101:4653

13. Dietz HP, Simpson JM (2008) Levator trauma is associated with pelvic organ prolapse. Bjog 115:979-984

14. DeLancey JO, Morgan DM, Fenner DE, Kearney R, Guire K, Miller JM et al (2007) Comparison of levator ani muscle defects and function in women with and without pelvic organ prolapse. Obstet Gynecol 109:295-302

15. Weemhoff MWM, Korsten L, Serroyen J, Kampschöer PHNM, Roumen FJME (2010) Postoperative catheterization after anterior colporrhaphy: 2 days versus 5 days. A multicentre randomized controlled trial. Int Urogynecol J 22:477-483

16. Shumaker SA, Wyman JF, Uebersax JS, McClish D, Fantl JA (1994) Health-related quality of life measures for women with urinary incontinence: the Incontinence Impact Questionnaire and the Urogenital Distress Inventory. Continence Program in Women (CPW) Research Group. Qual Life Res 3:291-306

17. van der Vaart $\mathrm{CH}$, de Leeuw JR, Roovers JP, Heintz AP (2003) Measuring health-related quality of life in women with urogenital dysfunction: the urogenital distress inventory and incontinence impact questionnaire revisited. Neurourol Urodyn 22:97-104

18. van Brummen HJ, Bruinse HW, van de Pol G, Heintz AP, van der Vaart CH (2006) Defecatory symptoms during and after the first pregnancy: prevalences and associated factors. Int Urogynecol J Pelvic Floor Dysfunct 17:224-230
19. Bump RC, Mattiasson A, Bo K, Brubaker LP, DeLancey JO, Klarskov $\mathrm{P}$ et al (1996) The standardization of terminology of female pelvic organ prolapse and pelvic floor dysfunction. Am J Obstet Gynecol 175:10-17

20. Dietz HP (2007) Quantification of major morphological abnormalities of the levator ani. Ultrasound Obstet Gynecol 29:329-334

21. Dietz HP, Steensma AB (2006) The prevalence of major abnormalities of the levator ani in urogynaecological patients. Bjog 113:225-230

22. Dietz HP, Bernando MJ, Kirby A, Shek KL (2011) Minimal criteria for the diagnosis of avulsion of the puborectalis muscle by tomographic ultrasound. Int Urogynecol J 22:699-704

23. Sand PK, Koduri S, Lobel RW, Winkler HA, Tomezsko J, Culligan PJ et al (2001) Prospective randomized trial of polyglactin 910 mesh to prevent recurrence of cystoceles and rectoceles. Am J Obstet Gynecol 184:1357-1362

24. Dietz HP, Chantarasorn V, Shek K (2010) Levator avulsion is a risk factor for cystocele recurrence. Ultrasound Obstet Gynecol $36: 76-80$

25. Diez-Itza I, Aizpitarte I, Becerro A (2007) Risk factors for the recurrence of pelvic organ prolapse after vaginal surgery: a review at 5 years after surgery. Int Urogynecol J Pelvic Floor Dysfunct 18:1317-1324

26. Ghetti C, Gregory WT, Edwards SR, Otto LN, Clark AL (2005) Pelvic organ descent and symptoms of pelvic floor disorders. Am J Obstet Gynecol 193:53-57

27. Jeon MJ, Chung SM, Jung HJ, Kim SK, Bai SW (2008) Risk factors for the recurrence of pelvic organ prolapse. Gynecol Obstet Invest 66:268-273

28. Salvatore S, Athanasiou S, Digesu GA, Soligo M, Sotiropoulou $M$, Serati M et al (2009) Identification of risk factors for genital prolapse recurrence. Neurourol Urodyn 28:301-304

29. Whiteside JL, Weber AM, Meyn LA, Walters MD (2004) Risk factors for prolapse recurrence after vaginal repair. Am J Obstet Gynecol 191:1533-1538

30. Smilen SW, Saini J, Wallach SJ, Porges RF (1998) The risk of cystocele after sacrospinous ligament fixation. Am J Obstet Gynecol 179:1465-1471 